\title{
Thermal Decomposition Behavior of Expandable Pattern Including Blended Metal or Metal Oxide Powder in Evaporative Pattern Casting of Al-Si System Alloy*
}

\author{
Takeshi Kobayashi and Toru Maruyama \\ Department of Material Science and Engineering, Faculty of Engineering, Kansai University, Suita 564-8680, Japan
}

We investigated thermal decomposition behavior of expanded patterns including thermal decomposition accelerators such as Ni, NiO, $\mathrm{CuO}$ and $\mathrm{Cu}_{2} \mathrm{O}$ (hereinafter referred to as "powder-blended expanded patterns") in an aluminum alloy evaporative pattern casting process; the following results were obtained. When these metal or metal oxide powders were blended in EPS (expandable polystyrene) patterns, an exothermic reaction occurred between metal or metal oxide powder and aluminum alloy melt. This reaction prevented, temperature drop at the top of the melt flow. In addition, these kinds of powder accelerated pattern thermal decomposition. As a result, the pattern thermal decomposition gas volume increased and aluminum alloy melt filling decreased.

(Received August 11, 2003; Accepted October 10, 2003)

Keywords: acceleration, aluminum alloy, evaporative pattern casting process, exothermic dissolution, exothermic reaction, expandable pattern, expandable polystyrene, oxide powder

\section{Introduction}

The melt filling mechanism in evaporative pattern casting is complex. The expandable polystyrene pattern (hereinafter referred to as "EPS pattern") is decomposed by the melt heat, the melt gradually filling the cavity (gas phase) thus generated. As the melt fills the pattern, the temperature at the top of the melt flow drops, rendering pattern thermal decomposition incomplete. As a result, a portion of the pattern is not gasified, and occasionally, generates liquefied resin, ${ }^{1)}$ which often causes residual (carbon) defects in castings. $^{2)}$

This study attempted to accelerate EPS pattern thermal decomposition in evaporative pattern casting of an $\mathrm{Al}-\mathrm{Si}$ alloy. We employed metal powder that causes exothermic reaction with aluminum alloy melt and dissolves into the melt, and several kinds of metal oxide powder that cause thermit reaction with aluminum alloy melt. EPS patterns blended with each of these kinds of powder were prepared. Al-Si alloy melt was poured into the patterns and the melt filling rate, thermal decomposition gas volume and temperature at top of melt flow were investigated.

\section{Experimental Procedure}

\subsection{Confirmation test for exothermic reaction of metal} or metal oxide powder with aluminum melt

As a metal that causes exothermic reaction with aluminum melt, metallic Ni was selected; as metal oxides, $\mathrm{NiO}, \mathrm{CuO}$ and $\mathrm{Cu}_{2} \mathrm{O}$ were selected. Particle size was less than $53 \mu \mathrm{m}$. For each of the above-mentioned metal and metal oxide powders, two end-sealed silica tubes $(\phi 3.5 \mathrm{~mm} \times 300 \mathrm{~mm})$ were prepared. A $3.00 \mathrm{~g}$ sample of each powder was mixed with colloidal silica of 5.0 mass $\%$, as bond. The mixture was then applied to the outer surface of one of the two tubes, over a length $30 \mathrm{~mm}$ from the sealed end, to make a candy-like silica tube that was then dried for $24 \mathrm{~h}$. Another tube was used

*This Paper was Presented at the 138th Meeting of Japan Foundry Engineering Society, held in Chiba, on May 12, 2001 without treatment. Using an electric resistance furnace and \#1 graphite crucible, $100 \mathrm{~g}$ of aluminum was melted. The candy-like silica tube and the untreated silica tube, were then immersed in the aluminum melt at a temperature of $1023 \mathrm{~K}$. $\mathrm{K}$ (JIS standard) thermocouples were inserted into the silica tubes and the temperature transition of both thermocouples was monitored.

\subsection{Manufacturing of expanded patterns blended with metal or metal oxide powder}

Using a spray-formed mold of Al-Zn alloy, expanded patterns with a volume of $182 \mathrm{~cm}^{3}(\phi 40 \mathrm{~mm} \times 145 \mathrm{~mm})$ were manufactured. In the case of the original patterns without blended metal or metal oxide powder (non-blended patterns), the mold was filled with $3.645 \mathrm{~g}$ of pre-expansion EPS beads (magnification of expansion: 40), set in an autoclave, heated and pressurized for 3.5 minutes under $55 \mathrm{kPa}$. The mold was then cooled with water until pattern temperature drops down to $333 \mathrm{~K}$. For powder-blended expanded patterns, $3.645 \mathrm{~g}$ pre-expansion EPS beads and metal or 0.055 or $0.109 \mathrm{~g}$ of metal oxide powder were put into an antistatic polyethylene sack. The sack was filled with air, sealed and shaken sufficiently to attach the powder to the surface of the beads. Since pre-expansion polystyrene beads are charged with static electricity, the powder adhered satisfactorily. The beads, thus coated with metal or metal oxide powder, were then formed into patterns in the same way as the abovementioned non-blended patterns.

\subsection{Casting design and pouring test}

The bottom pouring method was used to ensure that the aluminum melt flowed and filled the pattern calmly. Figure 1 shows the casting design for measuring melt filling rate and gas pressure. $\mathrm{A} \mathrm{CO}_{2}$ mold with a cross-sectional area of $1.96 \mathrm{~cm}^{2}$ was used for the runner. The gate cross-sectional area was $1.33 \mathrm{~cm}^{2}(\phi 13 \mathrm{~mm})$. Two powder-blended patterns were stacked together and connected to construct a single pattern with a total length of $250 \mathrm{~mm}$. As shown in Fig. 1, tungsten wires $(\phi 0.5 \mathrm{~mm})$ for use as touch sensors were inserted at positions $a$ to $f$ in the pattern. Each sensor was 


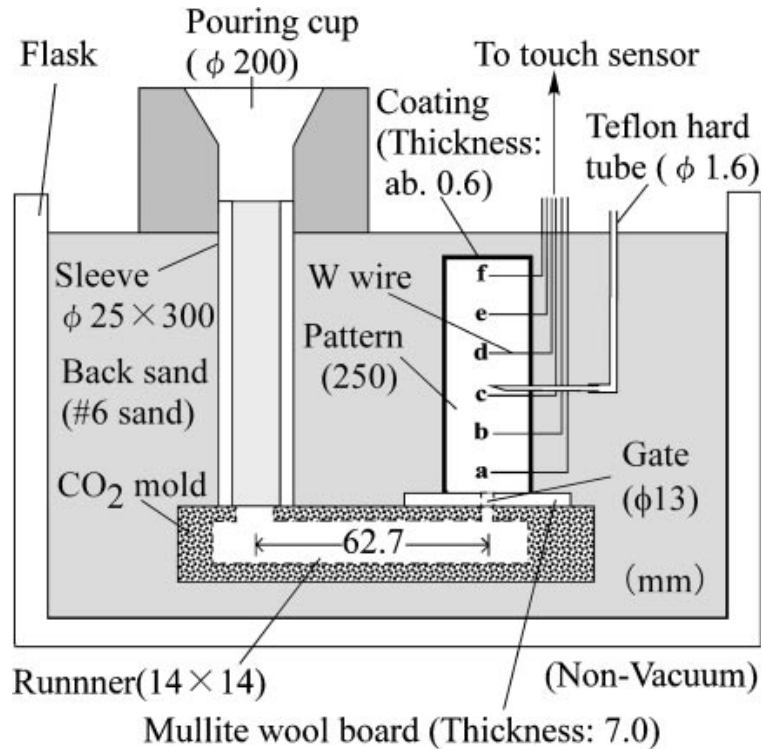

Fig. 1 Casting design for measured gas pressure and filling rate of melt.

connected with a $1.5 \mathrm{~V}$ battery cell; the order of melt contact with each touch sensor was recorded stepwise with a recorder. Diodes were built into the touch sensor circuit to avoid adverse electric current. To measure thermal decomposition gas pressure, a stainless pipe $\phi 1.3 \mathrm{~mm}$ was inserted at the position $c, 102 \mathrm{~mm}$ from the pattern bottom up to the pattern center. The pipe was connected to a pressure gauge through a Teflon hard tube and decomposition gas pressure was recorded with a recorder. Figure 2 shows a stepwise wave pattern indicating the order of contact and a gas pressure wave pattern. The pattern was then coated with

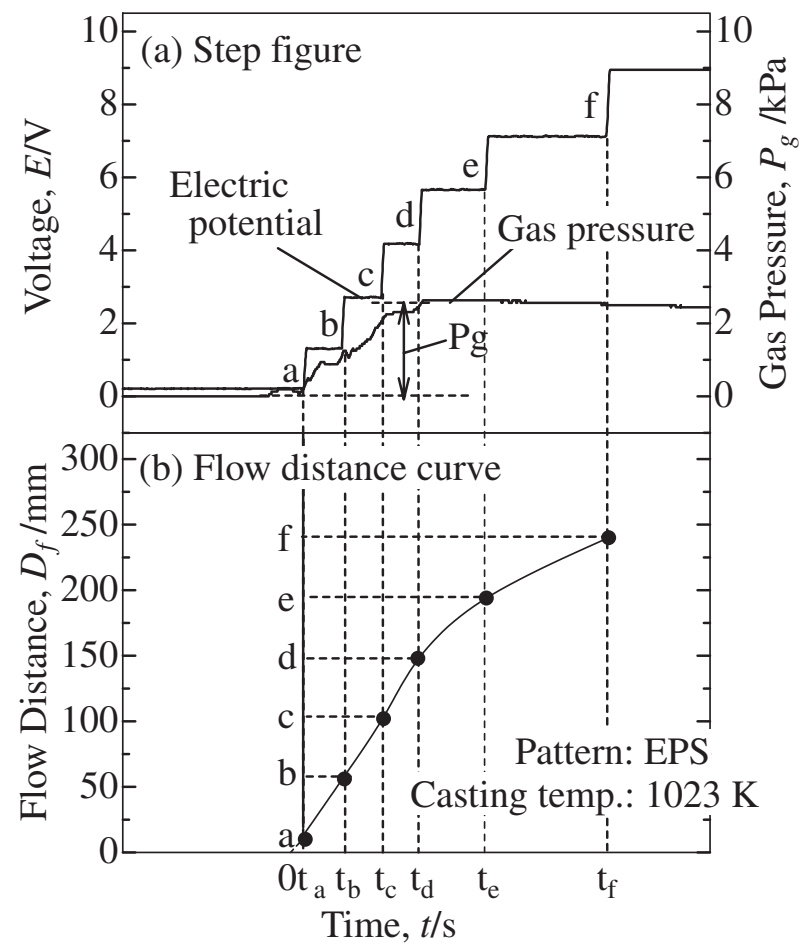

Fig. 2 Change of thermal decomposition gas pressure with passage time (a) and flow distance curve of melt (b). commercial coating material to a thickness of about $0.6 \mathrm{~mm}$ and naturally seasoned for 48 hours. Then the pattern was set vertically in a flask, which was filled carefully with \#6 silica sand and subjected to triaxial vibration (amplitude: $0.3 \mathrm{~mm}$; frequency: $40 \mathrm{~Hz}$; duration: $1 \mathrm{~min}$ ) to increase back sand density. Flask internal pressure was not reduced. Al-Si alloy melt was then poured into the powder-blended patterns at $1023 \mathrm{~K}$.

To examine melt temperature change in the powderblended pattern, we used a pattern similar to that mentioned above for filling rate and gas pressure measurement. $\mathrm{K}$ thermocouples were inserted instead of touch sensors (tungsten wires) and melt temperature was measured. In this experiment as well, the Al-Si alloy pouring temperature was $1023 \mathrm{~K}$. The gas pressure shows the tendency which gradually rises from $t_{\mathrm{a}}$ over $t_{\mathrm{c}}$. The cause of this phenomenon is because EPS pattern bead fusion is insufficient. So, gas pressure was sensed because gas reached the position of $c$ by passing through the beads, when decomposition of pattern started in between position of $a$ and $b$. Table 1 gives the chemical composition of the Al-Si alloy used here. The alloy contains $11.23 \% \mathrm{Si}$, near eutectic composition; it also contains $\mathrm{Ni}, \mathrm{Cu}$ and $\mathrm{Mg}$.

\subsection{Pattern thermal decomposition gas volume meas- urement}

Casting was made using powder-blended patterns $(\phi 40 \mathrm{~mm} \times \mathrm{L} 145 \mathrm{~mm})$; thermal decomposition gas was collected as shown in Fig. 3. That is, a $\phi 3 \mathrm{~mm}$ hole was bored at the pattern center, an aluminum U-shaped pipe (half pipe) was inserted into the hole, and then into a silica tube $\phi 4 \mathrm{~mm}$

Table 1 Chemical composition of Al-Si alloy. (mass\%)

\begin{tabular}{ccccc}
\hline $\mathrm{Si}$ & $\mathrm{Ni}$ & $\mathrm{Cu}$ & $\mathrm{Mg}$ & $\mathrm{Fe}$ \\
\hline 11.23 & 2.23 & 2.30 & 0.41 & 0.15 \\
\hline
\end{tabular}

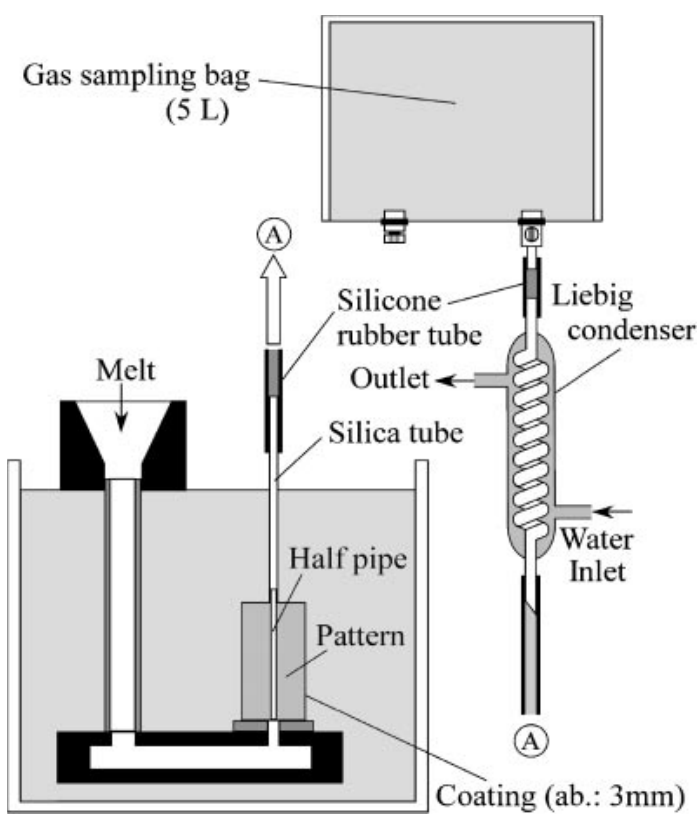

Fig. 3 Schematic illustration of casting design and measurement method of thermal decomposition gas volume. 
$\times 300 \mathrm{~mm}$ at the top position of the pattern. The U-shaped pipe and silica tube were then joined together with mold adhesion bond to prevent leakage of decomposition gas. The silica tube was connected to a Liebig condenser, to lead decomposition gas into a gas-sampling bag after cooling. The gas temperature in the bag was $298 \mathrm{~K}$. Gas was then led from the gas-sampling bag into a syringe $(200 \mathrm{ml})$, where gas volume was measured precisely. Pattern coating thickness was approximately $1 \mathrm{~mm}$; the pattern was used after natural seasoning for 48 hours. The Al-Si alloy was poured at a temperature of $1023 \mathrm{~K}$.

Experimental result reproducibility was achieved by precisely controlling coating layer thickness and casting temperature.

\section{Experimental Results and Discussion}

\subsection{Confirmation of exothermic reaction of metal or metal oxide powder with pure aluminum melt}

Dipping tests were conducted in which candy-like silica tubes coated with various kinds of metal and metal oxide powder were dipped in pure aluminum melt, as previously mentioned. Figure 4 shows the relation between melt temperature and dipping time in the dipping test for a silica tube coated with Ni powder. The datum shown in the figure with "Al melt" is the temperature of the silica tube without coating. The temperature of the silica tube coated with $\mathrm{Ni}$ powder is increased. Temperature rise $\Delta T$ is $45.3 \mathrm{~K}$. In all cases of coating with $\mathrm{Ni}, \mathrm{CuO}$ or $\mathrm{Cu}_{2} \mathrm{O}$ powder, the temperature increased. Figure 5 shows the results of temperature difference $\Delta T$ between pure aluminum melt and silica tubes coated with metal or metal oxide powder. The temperature rise values for $\mathrm{Ni}$ and $\mathrm{NiO}$ powder were found to be remarkable. When metallic Ni (solid) is added into aluminum melt, exothermic dissolution of metallic Ni takes place. $^{4)}$

$\mathrm{Ni}$ causes combustion-synthesis reaction with $\mathrm{Al}$, to form AlNi. ${ }^{4)}$ Similarly, NiO causes thermit type combustionsynthesis reaction with $\mathrm{Al}$ to form $\mathrm{AlNi}$ and $\mathrm{Al}_{2} \mathrm{O}_{3}{ }^{5)} \mathrm{CuO}$ and $\mathrm{Cu}_{2} \mathrm{O}$ also cause thermit type reaction to form $\mathrm{Al}_{2} \mathrm{O}_{3}$.

The reaction formulae and standard free energy of formation $\Delta G^{\circ}$ are shown below.

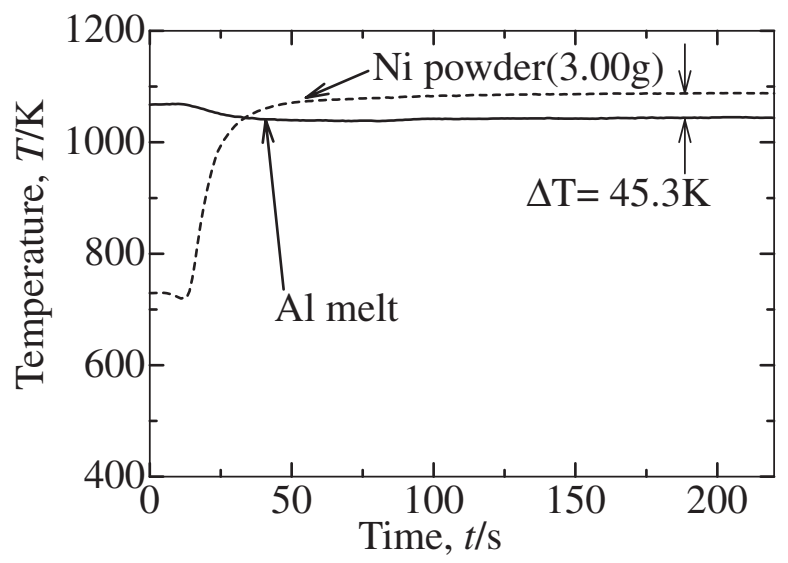

Fig. 4 Relation between pure aluminum melt temperature and dipping time on dipping test of coating layer with $\mathrm{Ni}$ powder.

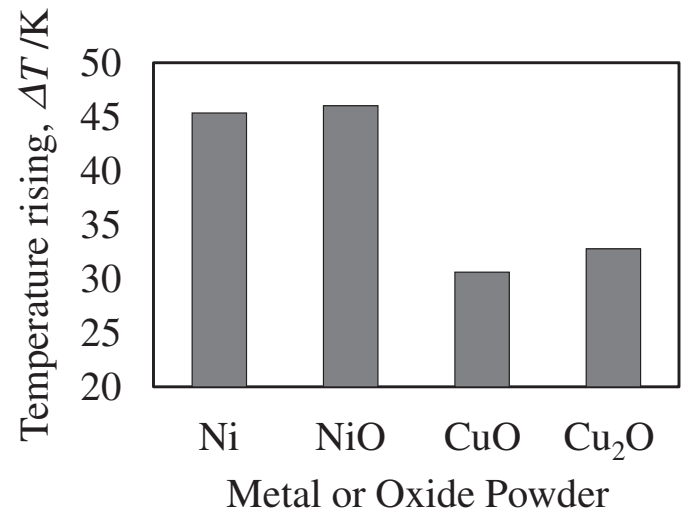

Fig. 5 Comparison with temperature rising of metal or various metal oxide powder.

$\bigcirc$ Combustion-synthesis reaction

$$
\mathrm{Al}+\mathrm{Ni}=\mathrm{AlNi} \Delta G^{\circ}{ }_{298}=-117.2\left(\mathrm{~kJ} \cdot \mathrm{mol}^{-1}\right)^{7-9)}
$$

OThermit type combustion-synthesis reaction

$$
\begin{aligned}
5 \mathrm{Al}+3 \mathrm{NiO} & =3 \mathrm{AlNi}+\mathrm{Al}_{2} \mathrm{O}_{3} \Delta G^{\circ}{ }_{298} \\
& =-1298.8\left(\mathrm{~kJ} \cdot \mathrm{mol}^{-1}\right)^{7,9-11)}
\end{aligned}
$$

OThermit reaction

$$
\begin{aligned}
2 \mathrm{Al}+3 \mathrm{CuO} & =3 \mathrm{Cu}+\mathrm{Al}_{2} \mathrm{O}_{3} \Delta G^{\circ}{ }_{298} \\
& =-1197.0 \quad\left(\mathrm{~kJ} \cdot \mathrm{mol}^{-1}\right)^{7,11,12)} \\
2 \mathrm{Al}+3 \mathrm{Cu}_{2} \mathrm{O} & =6 \mathrm{Cu}+\mathrm{Al}_{2} \mathrm{O}_{3} \Delta G_{298}^{\circ} \\
& =-1138.2 \quad\left(\mathrm{~kJ} \cdot \mathrm{mol}^{-1}\right)^{7,11,13)}
\end{aligned}
$$

For qualitative comparison, the heat quantity in using metal or metal oxide powder of quantity equal to that in the dipping test was calculated from the equation. The calculated values $(\mathrm{kJ})$ were 6.0, 17.3, 15.1 and 8.0 in the case of $\mathrm{Ni}, \mathrm{NiO}$, $\mathrm{CuO}$ and $\mathrm{Cu}_{2} \mathrm{O}$, respectively. Though in calculated value $\mathrm{Ni}$ is the smallest, in the temperature rise shown in Fig. 5 it is large for $\mathrm{NiO}$ next. The cause of these differences seems to be a difference in reaction rate between powder and melt. Actually, it was the shortest in the time until the temperature of the silica tube coated with $\mathrm{Ni}$ powder reached melt temperature from dipping start of the silica tube; next were $\mathrm{NiO}, \mathrm{Cu}_{2} \mathrm{O}$ and $\mathrm{CuO}$, in that order.

In any case, it can be expected that these kinds of metal and metal oxide powder dealt with here cause exothermic reaction with aluminum melt and accelerate thermal decomposition of expanded patterns. The $\mathrm{Al}_{2} \mathrm{O}_{3}$ formed in eqs. (2), (3) and (4) is thought to be small in amount and to pose no problem in casting production.

\subsection{Change in melt filling rate, thermal decomposition gas pressure and melt temperature in evaporative pattern casting}

Figure 6 shows the effects of powder-blended pattern metal or metal oxide powder blending ratio on melt filling rate and thermal decomposition gas pressure. Figure 7 shows the relation between distance from pattern bottom and temperature difference $(\Delta T)$ of the melt for each blending ratio. Temperature difference $\Delta T$ means the difference 


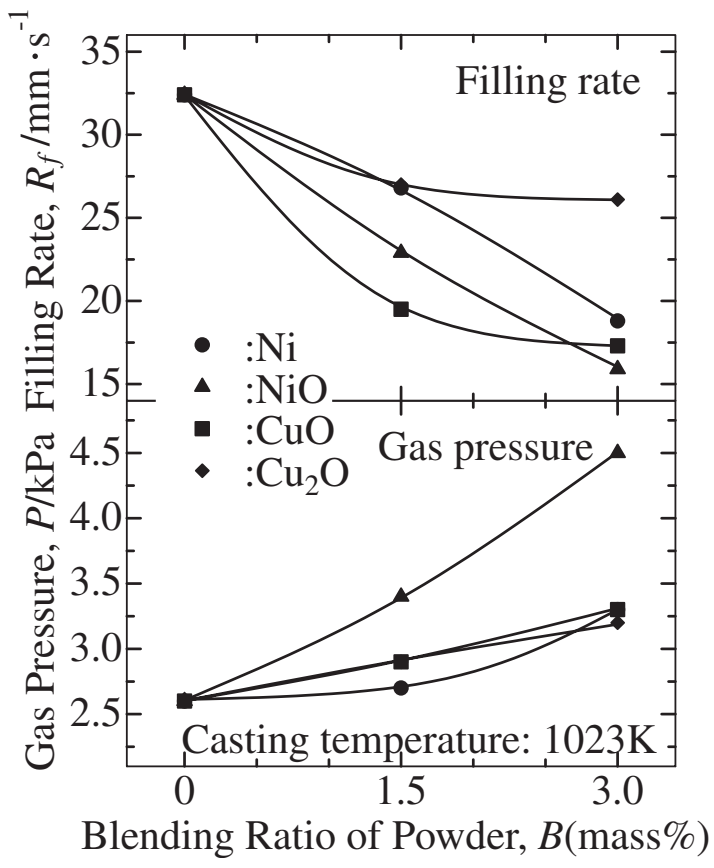

Fig. 6 Effects of blending ratio of metal or metal oxide powder on filling rate and decomposition gas pressure.

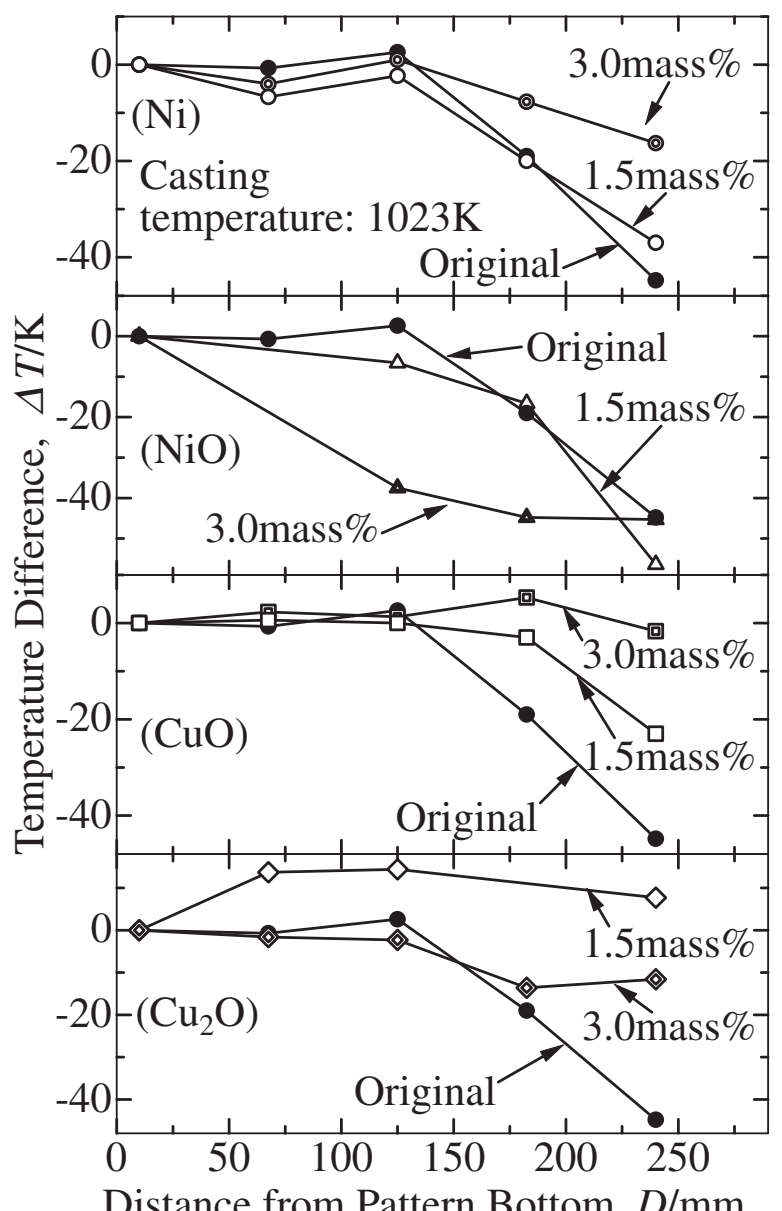

Fig. 7 Relation between distance from expandable pattern bottom and temperature difference $(\Delta T)$ in Al-Si system alloy melt. between the reference temperature and the temperature at various distances from the pattern bottom, when reference temperature is defined as the melt temperature at a point of $10 \mathrm{~mm}$ from the pattern bottom. Here, the measured temperature at each position is the maximum temperature after melt arrival. When the temperature at the position in question exceeds the reference temperature, $\Delta T$ is represented as positive. As seen in Fig. 6, with the increase in metal or metal oxide powder blending ratio, thermal decomposition gas pressure is increased; accordingly, the melt filling rate is decreased remarkably. It is considered that since the specific gravity of Al-Si alloy is less than those of cast iron and copper alloys, the melt is pushed back toward the gate; as a result, the filling rate is decreased drastically. As for Fig. 7, excepting the pattern blended with $\mathrm{NiO}$ powder, the absolute values of temperature difference $\Delta T$ at the pattern top for other powder-blended patterns are lower than that for the original (non-blended) pattern. This means that the temperature at the top of the powder-blended patterns is higher. For the pattern blended with $\mathrm{Cu}_{2} \mathrm{O}$ of 1.5 mass $\%$ in particular, the temperature is higher at the pattern top (positive value) than at the bottom (reference value). These phenomena suggest that melt and blended powder have reacted exothermically. The prevention effect of the temperature drop at the top of the melt flow of $\mathrm{CuO}$ and $\mathrm{Cu}_{2} \mathrm{O}$ is greater than that of $\mathrm{Ni}$ and $\mathrm{NiO}$. This tends to be the reverse of the result seen in Fig. 5. On the other hand, even assuming that a maximum 3.0 mass $\%$ of metal or metal oxide powder blended into a pattern is completely contained in the aluminum alloy casting, the content of metal or oxide in the casting is no more than $0.023 \%$. It can hardly be concluded that the exothermic reaction of such a small amount of metal or metal oxide powder would cause melt temperature to rise as high as $30 \mathrm{~K}$. Therefore, it is considered that in addition to the exothermic reaction of the melt with powder, the catalytic action of the metal or metal oxide powder blended into the pattern accelerates pattern thermal decomposition. $\mathrm{NiO}$ powder, it is considered that it hardly causes exothermic reaction with the aluminum alloy melt, but produces a rather strong catalytic action. Therefore, we suggest that the expanded pattern blended with $\mathrm{NiO}$ powder is thermally decomposed by catalytic action.

\subsection{Thermal decomposition of powder-blended pattern gas volume}

Figure 8 shows the effect of metal or metal oxide powder blending ratio on thermal decomposition gas volume. With increased powder blending ratio, thermal decomposition gas volume increases. $\mathrm{CuO}$ powder produces the greatest volume of decomposition gas; a blending ratio 3.0 mass $\%$ produces three times the volume produced in the non-blended (original) pattern. These results show that the metal and metal oxides used in this study accelerate thermal decomposition of EPS patterns and increase decomposition gas volume. Owing to the increased thermal decomposition gas volume, gas pressure is increased as shown in Fig. 6. The fact (as demonstrated in Fig. 6) that melt filling rate decreases with increase in blending ratio clearly shows that the melt is pushed back toward the gate by the increased gas pressure. 


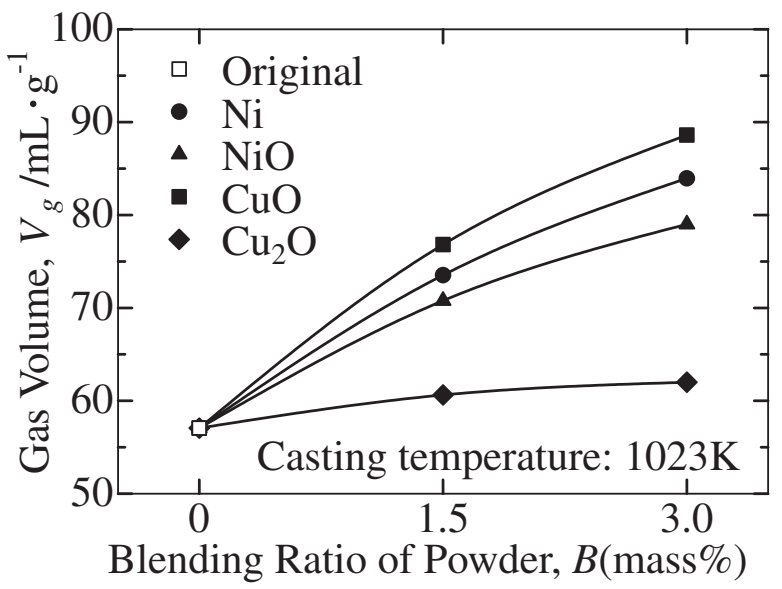

Fig. 8 Effects of blending ratio of metal or metal oxide powder in expandable pattern on the decomposition gas volume.

\subsection{Surface appearance and cast structure of aluminum alloy castings}

Figure 9 shows the surface appearance of castings cast into powder-blended patterns. In the photographs of the top and side surface of the casting made using the original pattern, clear shape of expandable beads is closely printed. On the other hand, in the patterns blended with $\mathrm{NiO}, \mathrm{CuO}$ and $\mathrm{Cu}_{2} \mathrm{O}$, the shape of beads on the top surface of the castings has collapsed. Particularly in the pattern blended with $\mathrm{Cu}_{2} \mathrm{O}$, shrinkage is observed. This seems to be a result of the difference between melt temperature at the tip. The shrinkage cavity does not arise with casting in a non-blended pattern, due to the low melt temperature at the tip and the fact that the casting solidifies from the upper part, while melt is supplied from the lower. On the other hand, melt temperature at the tip rises with casting in powder-blended patterns, solidification of the casting upper part slowing in comparison with the non-

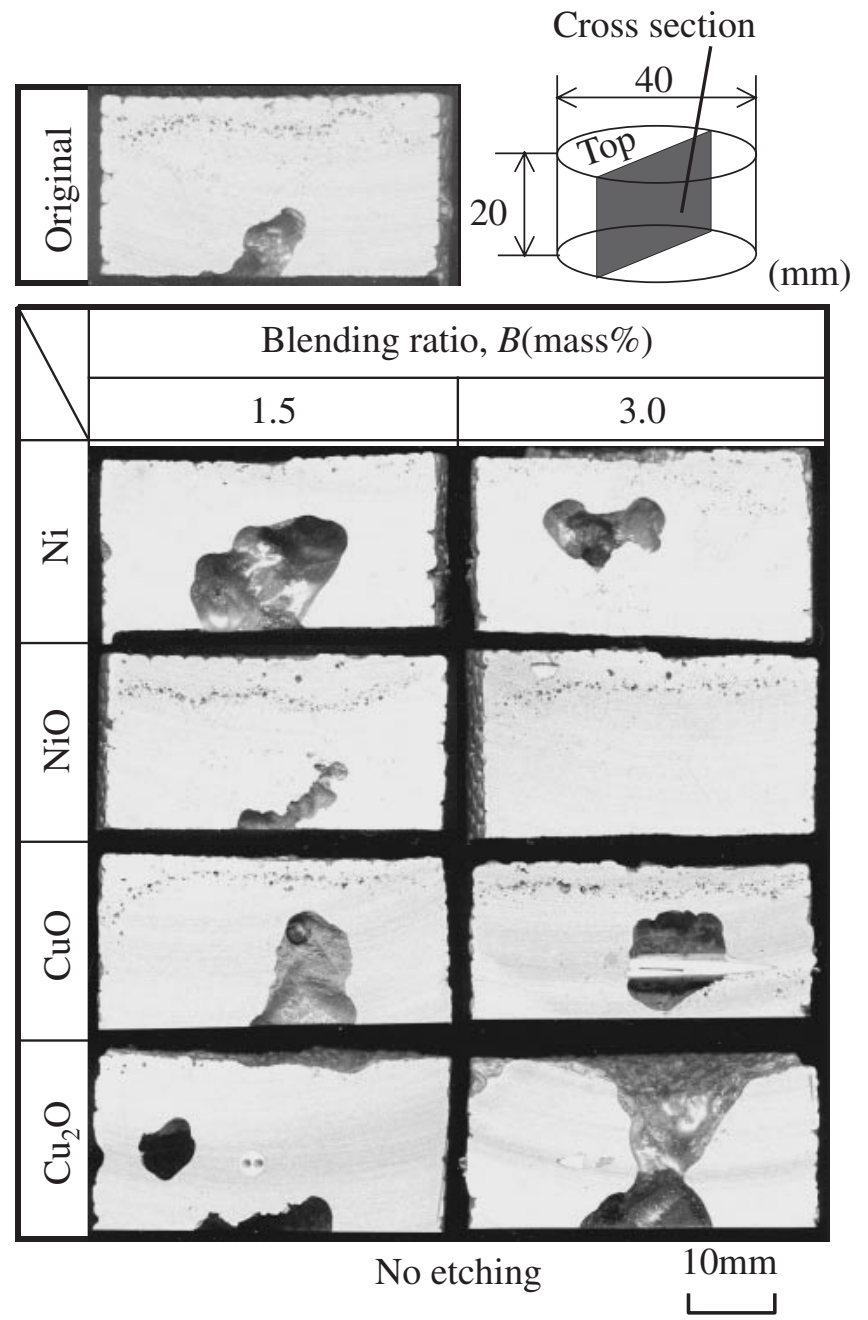

Fig. 10 Relation between blending ratio of powder and macrostructure on cross section of $\mathrm{Al}$ alloy casting top.

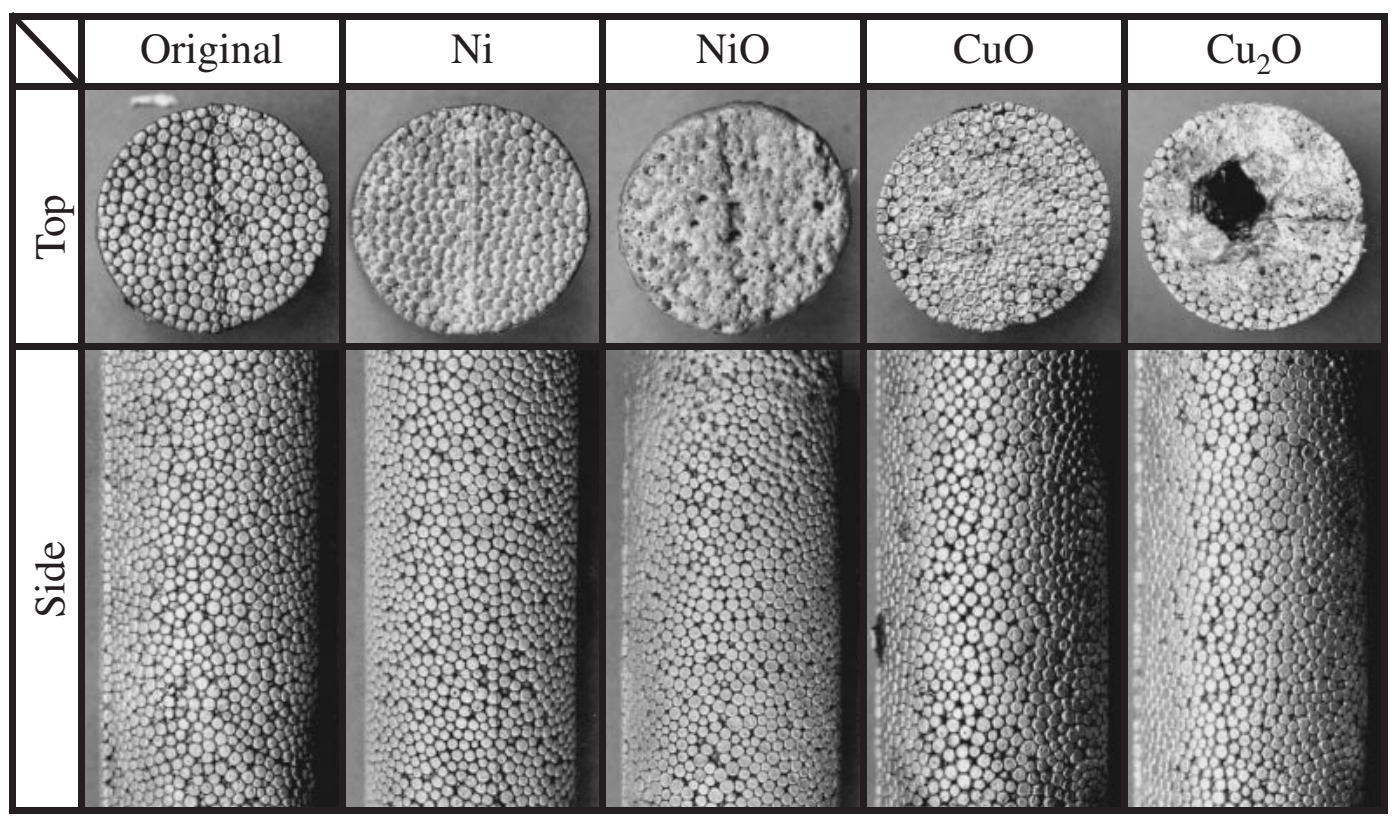

Powder: $3.0 \mathrm{mass} \%$ 


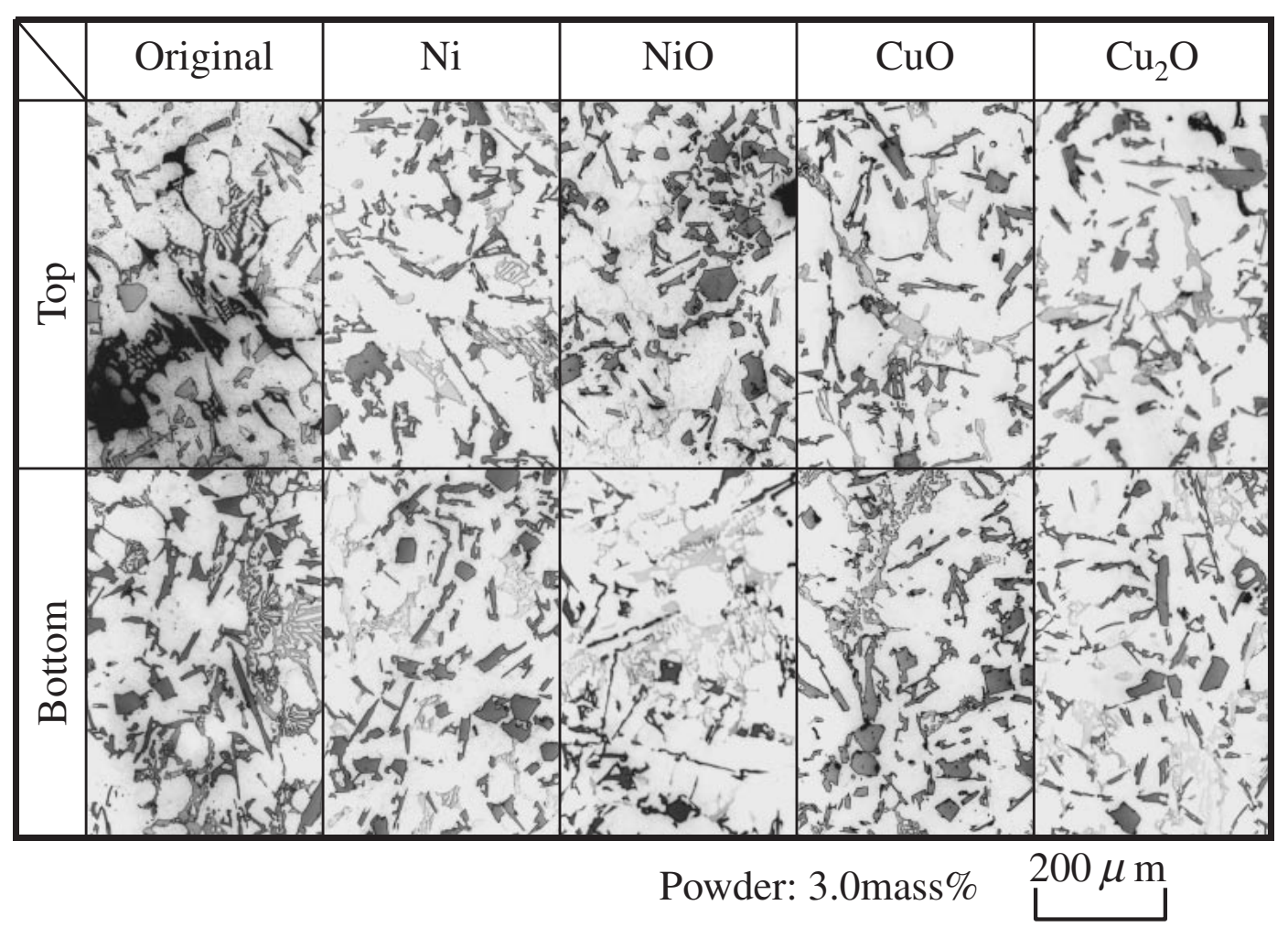

Fig. 11 Microstructure of casting on various blended patterns with metal or metal oxide.

blended pattern. As a result, the melt supply stops before the macro solidification shrinkage in the upper part of the casting, and the shrinkage cavity seems to arise. A the side surface photographs of castings made using the powderblended patterns clearly show the shape of expandable beads is closely printed.

Figure 10 shows the macrostructures in vertical cross sections at the top of castings made with powder-blended patterns. In the original pattern and those blended with $\mathrm{NiO}$ and $\mathrm{CuO}$, a large number of small porosities are visible in the area several millimeters from the casting top. In the patterns blended with $\mathrm{Ni}$ and $\mathrm{Cu}_{2} \mathrm{O}$, no porosity is observed. Porosity is observed when the ratio of metallic atoms to oxygen atoms in the oxides is $1: 1$, which fact suggests that porosity is generated easily when the oxygen in the oxide is high. Although some inside shrinkage cavities are observed in the upper region for all castings, it may be possible to eliminate them by modifying the casting design.

Figure 11 shows microstructures at the tops and bottoms of castings. The acicular precipitates observed in those structures are eutectic Si precipitates and intermetallic compounds of Ni with Al. The kind and amount of powder blended in the pattern cause no change in the cast structure.

\section{Conclusion}

$\mathrm{Ni}, \mathrm{NiO}, \mathrm{CuO}$ and $\mathrm{Cu}_{2} \mathrm{O}$ were blended in expanded patterns as thermal decomposition accelerators, and the thermal decomposition behavior of these patterns in evaporative pattern casting of an aluminum alloy were investigated. The following results were obtained.

It was confirmed that these kinds of metal or metal oxide powder cause exothermic reaction with aluminum melt. In powder-blended patterns, these kinds of powder prevented temperature drop at the top of the aluminum alloy melt flow and accelerated pattern thermal decomposition. This increased decomposition gas volume and gas pressure, which in turn decreased the aluminum alloy melt filling rate.

\section{REFERENCES}

1) T. Kobayashi and Y. Kasuya: IMONO 64 (1992) 192-197.

2) T. Kobayashi and Y. Kasuya: IMONO 64 (1992) 318-324.

3) T. Kobayashi, T. Maruyama, M. Kano and M. Hotta: "Kankyotekiougata sokeizai kinozairyou kaihatsu”, Research Report I, The Institute of Industrial Technology of Kansai University (2001) pp. 120-140.

4) I. Song and N. Thadhani: Metall. Trans. A 23A (1992) 41-48.

5) O. Yamada and H. Matsumoto: IMONO 67 (1995) 708-715.

6) S. Odawara: New ceramics 4/9 (1991) 79-83.

7) O. Knacke, O. Kucbschewski and K. Hesselmann: Thermochemical properties of inorganic substances 2nd ed. Part 1, (Springer-Verlag, Berlin, 1991) pp. 19.

8) O. Knacke, O. Kucbschewski and K. Hesselmann: Thermochemical properties of inorganic substances/2nd ed. Part 2, (Springer-Verlag, Berlin, 1991) pp. 1438.

9) I. Barin, O. Kancke and O. Kubaschewski: Thermodinamic Properties of Inorganic Substances/supplement, (Springer-Verlag, Berlin and New York, 1977) pp. 490.

10) O. Knacke, O. Kucbschewski and K. Hesselmann: Thermochemical properties of inorganic substances/2nd ed. Part 2, (Springer-Verlag, Berlin, 1991) pp. 1455.

11) O. Knacke, O. Kucbschewski and K. Hesselmann: Thermochemical properties of inorganic substances/2nd ed. Part 1, (Springer-Verlag, Berlin, 1991) pp. 47.

12) O. Knacke, O. Kucbschewski and K. Hesselmann: Thermochemical properties of inorganic substances/2nd ed. Part 1, (Springer-Verlag, Berlin, 1991) pp. 602.

13) O. Knacke, O. Kucbschewski and K. Hesselmann: Thermochemical properties of inorganic substances/2nd ed. Part 1, (Springer-Verlag, Berlin, 1991) pp. 601. 